\title{
Ilizarov External Fixation: Percutaneous Gigli Saw Versus Multiple Drill-hole Osteotomy Techniques for Distraction Osteogenesis
}

\author{
Asadullah Makhdoom ${ }^{1}$, Jagdesh Kumar $^{2}$, Adeel A. Siddiqui ${ }^{2}$ \\ 1. Orthopaedic Surgery \& Traumatology, Liaquat University of Medical \& Health Sciences, Jamshoro, PAK 2. \\ Orthopaedic Surgery, Dow University of Health Sciences, Karachi, PAK
}

Corresponding author: Jagdesh Kumar, jagdesh@doctor.com

\section{Abstract \\ Introduction}

Many different methods and variations have been employed to perform osteotomy for deformity correction, bone lengthening, and segmental bone transport. Currently, multiple drill-hole (MDH) and Gigli saw osteotomies are the two most preferred ones, being favoured over other techniques. Our objective is to compare the modified healing index (mHI) of these two commonly used procedures.

\section{Methodology}

This retrospective study was conducted at the department of Orthopedics, Liaquat University of Medical and Health Sciences, Jamshoro, Pakistan. The study population consisted of all skeletally mature patients who underwent tibial bone osteotomy for bone lengthening or bone transport using Ilizarov circular fixator from June 2016 to September 2018. We excluded patients with metabolic bone disease and patients who underwent osteotomy for deformity correction. Preoperative and operative patients' demographics and clinical data were gathered through a review of medical record and $\mathrm{mHI}$ was calculated to compare the effectiveness of osteotomy techniques.

\section{Results}

A total of 50 patients, $74 \%$ males and $26 \%$ females $26 \%$ with a mean age of $33.14 \pm 12$ years were included in the study. Of the 50 patients, 23 (27 osteotomies) had undergone MDH osteotomy (group I), whereas 27 patients (37 osteotomies) had a Gigli saw osteotomy (group II). The overall mHI of both groups was $1.60 \pm$ $0.34 \mathrm{month} / \mathrm{cm}$ (range 1.0-2.5 month/cm). When we compared the $\mathrm{mHI}$ of both techniques, the mean mHI was $1.72 \pm 0.33 \mathrm{month} / \mathrm{cm}$ (range $1.2-2.5 \mathrm{months} / \mathrm{cm}$ ) in MDH group and $1.54 \pm 0.36 \mathrm{month} / \mathrm{cm}$ (range 1.0$2.5 \mathrm{month} / \mathrm{cm}$ ) in the Gigli saw group. The healing index was significantly lower in the Gigli saw group. None of our patients showed nonunion at the osteotomy site. However, the problems of incomplete osteotomy in two cases and bone fractures in four cases were seen in MDH osteotomy.

Received 05/31/2019

Review began 06/09/2019 Review ended 06/10/2019 Published 06/22/2019

\section{(๑) Copyright 2019}

Makhdoom et al. This is an open access article distributed under the terms of the Creative Commons Attribution License CC-BY 3.0., which permits unrestricted use, distribution, and reproduction in any medium, provided the original author and source are credited.

\section{Conclusion}

According to our results, percutaneous Gigli saw osteotomy technique by two small incisions minimizes the local soft tissue trauma and periosteal disruption around the osteotomy more than the multiple drill holes osteotomy, resulting in better consolidation following distraction osteogenesis.

Categories: Orthopedics, Trauma

Keywords: distraction osteogenesis, gigli saw, multiple drill holes, osteotomy

\section{Introduction}

Osteotomy was popularized by Professor Gavril Abramovich Ilizarov in the 1950s, and since that time, many different methods to perform osteotomy have been described for deformity correction, bone lengthening, and segmental bone transport [1-2]. An ideal osteotomy technique is one that minimizes soft tissue and periosteal disruption, lessens thermal necrosis, and produces high-quality healing tissue [1]. These goals can be accomplished with a technique that is truly minimally invasive and preserves the medullary, as well as periosteal blood supply [3-4].

Currently, multiple drill-hole (MDH) and Gigli saw osteotomy are the two foremost methods for osteotomy, being favoured and recommended by many orthopedic surgeons [3-6]. Recently, several studies have evaluated their outcome and reported the best results for quality of the regenerated bone in comparison with other methods of osteotomy $[2,7]$.

Most of the published studies have evaluated the clinical and radiological outcome of Ilizarov fixator. There 
is a paucity of data comparing the difference in healing indices between percutaneous Gigli saw and MDH osteotomy techniques in patients undergoing distraction osteogenesis. Hence, the purpose of this study was to evaluate if there is a difference in the modified healing index ( $\mathrm{mHI}$ ) of percutaneous Gigli saw compared with MDH osteotomy.

\section{Materials And Methods}

This retrospective and quasi-experimental study with consecutive non-probability sampling of patients was undertaken at the department of Orthopedic Surgery, Liaquat University of Medical and Health Sciences, Jamshoro, Pakistan. The study population consisted of all skeletally mature patients who underwent tibial bone osteotomy for bone lengthening or transport using Ilizarov circular fixator, in a two year period from June 2016 to September 2018. We excluded patients with metabolic bone disease and those who underwent osteotomy for deformity correction. All osteotomies of tibial bone were performed by a senior orthopedic surgeon, by using the previously presented standard surgical technique.

Patients were divided into two groups; Group I included 23 patients in which MDH osteotomy was performed and Group II included 27 patients in which Gigli saw osteotomy was performed. In the postoperative period, all patients followed the same rehabilitation protocol and were reviewed bi-weekly during the distraction period, and then monthly until radiological signs of consolidation of the regenerated bone were observed.

Consolidation time was defined as the time from the beginning of distraction until the full strengthening of regenerated bone, defined by the formation of three of four complete cortices at least $2 \mathrm{~mm}$ in thickness of the regenerated bone in two orthogonal radiograms. Preoperative and operative patients' demographics and clinical data including age, gender, surgical indications, technique of osteotomy, level of osteotomy, consolidation time, and follow-up duration were gathered through a review of the medical record. $\mathrm{mHI}$ (consolidation time per centimeter of lengthening instead of total time in the frame) was calculated to compare the effectiveness of osteotomy technique [7]. We used this modification because in some patients tibial bone osteotomy was already consolidated, but there was considerable delay in waiting for the transport docking site to unite.

The data were entered and analyzed in IBM Statistical Package for the Social Sciences Statistics for Windows, Version 22.0 (IBM Corp., Armonk, NY). Data are reported as mean and standard deviation (SD). Student ttest and Fisher's exact test was used to compare non-parametric means. A p-value of $\leqslant 0.05$ was taken as significant.

\section{Results}

A total of 64 osteotomies were performed in 50 patients out of which 37 were males (74\%) and 13 were females (26\%) with a mean age of $33.14 \pm 12$ years. The patients were grouped into two: Group I was offered $\mathrm{MDH}$ osteotomy whereas Group II was offered a Gigli saw osteotomy. Overall, 38 osteotomies were performed at the proximal tibia and 26 were performed at the distal tibia (Table 1). Indications for which osteotomies were performed are mentioned in Table 1. A pictorial representation of the entire process in a single patient is given in Figures 1-4. 


\section{Cureus}

Characteristics

n (\%)

Number of tibial osteotomies $(n=64)$

Gigli Saw

$37(58.8 \%)$

Multiple drill-hole

$27(42.2 \%)$

Location

Proximal tibia

$38(59.4 \%)$

Distal tibia

Surgical indication

Limb lengthening due to limb lengthening discrepancy

Congenital

Post-poliomyelitis

Post-traumatic

$11(22 \%)$

Bone transport due to bone defect

Post-traumatic

Chronic osteomyelitis

After bone tumor excision

$03(6 \%)$

\section{TABLE 1: Surgical characteristics of patients}

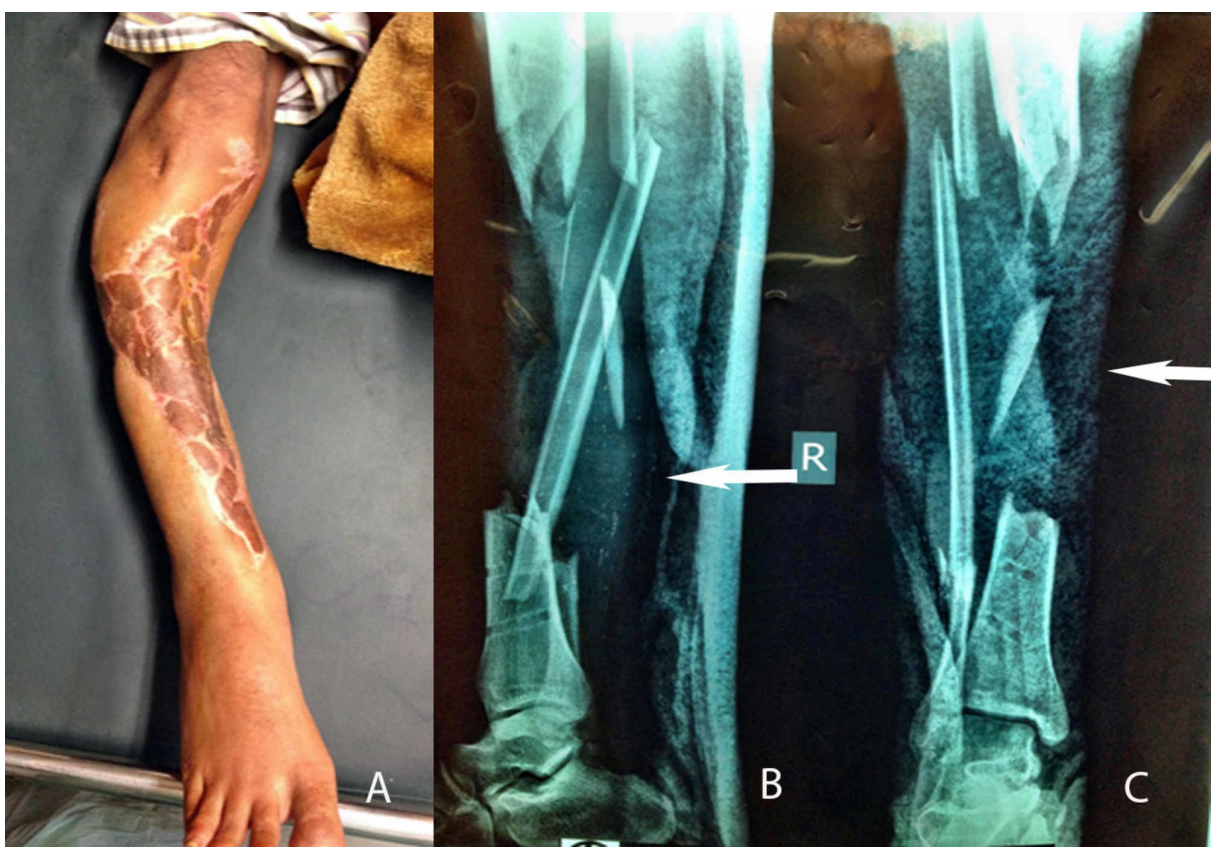

FIGURE 1: Preoperative pictures of post-traumatic bone defect with a live view (1A), lateral radiographic view (1B), and anteroposterior radiographic view $(1 \mathrm{C})$ 


\section{Cureus}

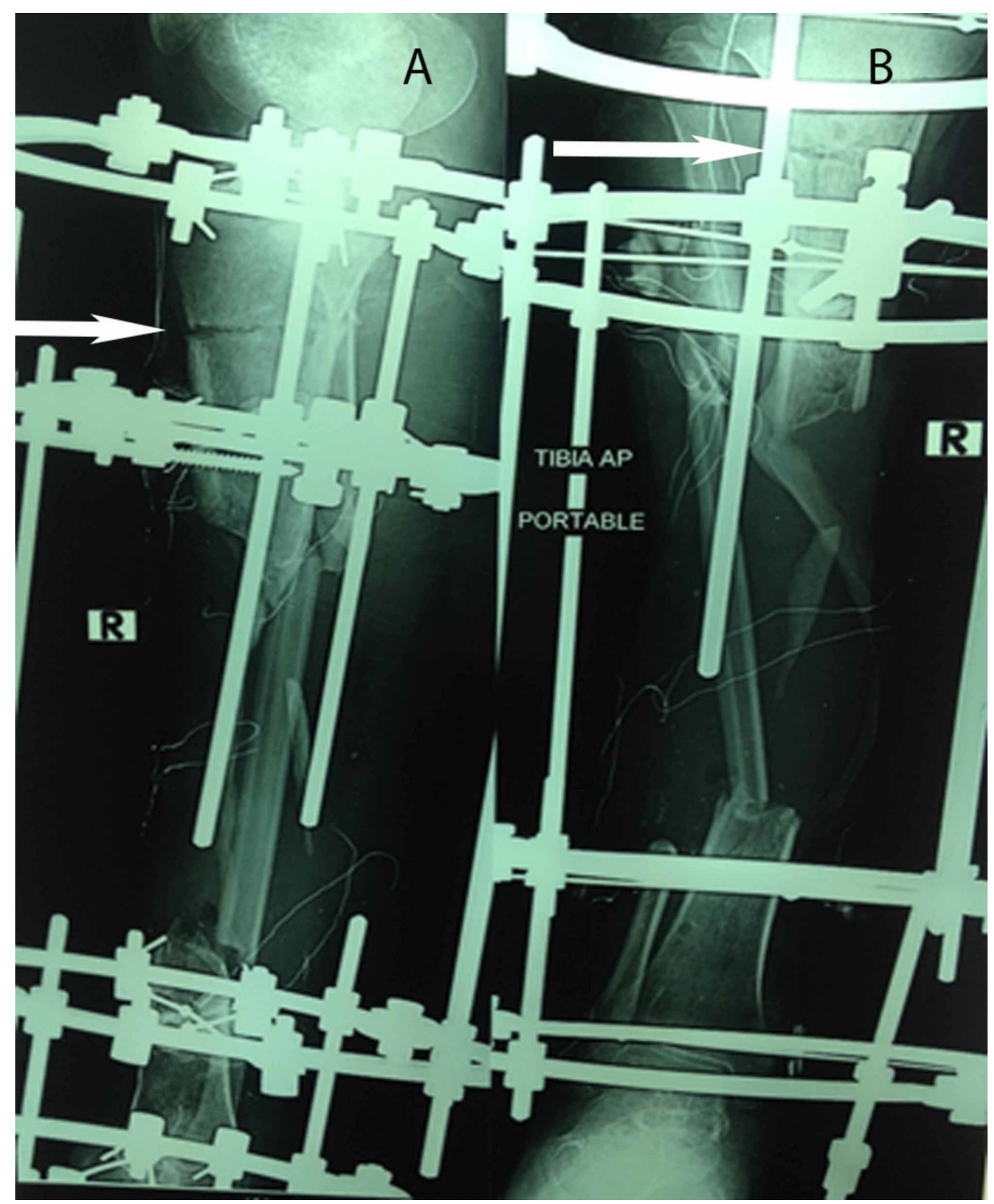

FIGURE 2: Immediate postoperative plain radiographs of the same patient who underwent multiple drill-hole osteotomy, with an anteroposterior (AP) view (2A) and a posteroanterior view (2B) 


\section{Cureus}

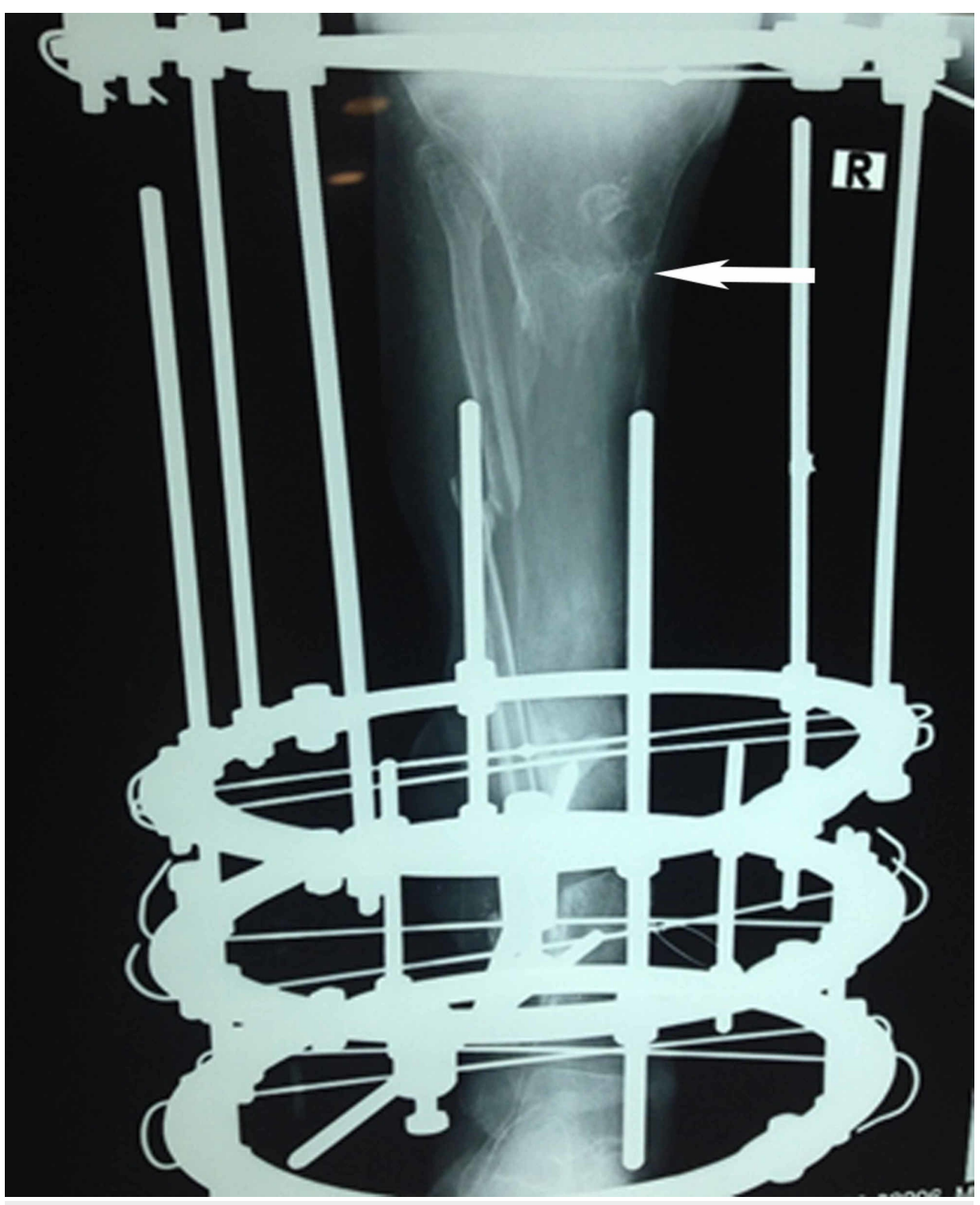

FIGURE 3: Postoperative plain radiograph of the same patient 13 months following the completion of bone transport showing the healed osteotomy site 


\section{Cureus}

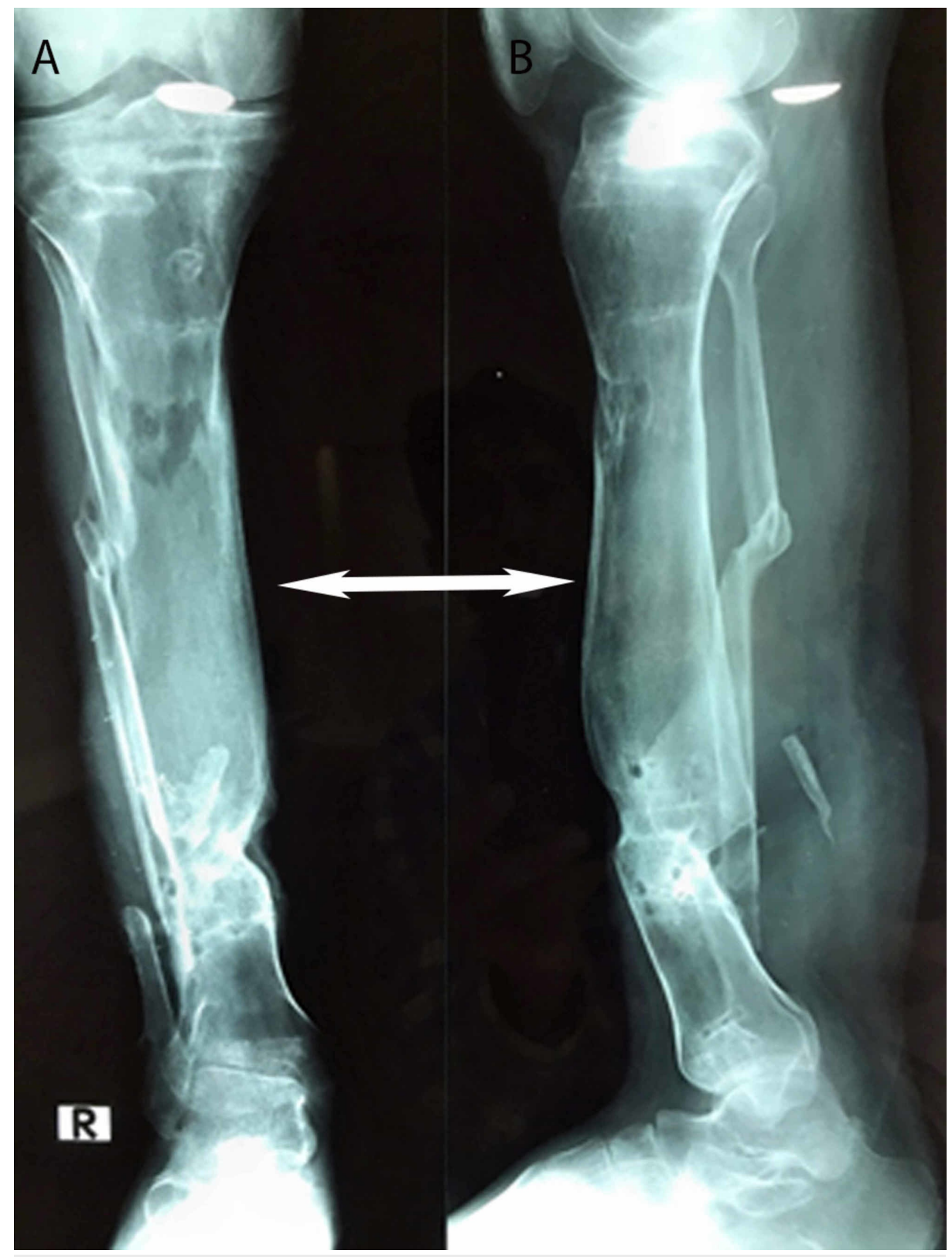

FIGURE 4: Postoperative plain radiographs of the same patient after removal of the llizarov frame, showing good regeneration of bone with an anteroposterior view (4A) and a lateral view (4B)

The overall $\mathrm{mHI}$ of both groups came out to be $1.60 \pm 0.34 \mathrm{month} / \mathrm{cm}$ (range 1.0-2.5 month/cm). The $\mathrm{mHI}$ was compared between genders, the level of osteotomy, and both the techniques as shown in Table 2 . When we compared the $\mathrm{mHI}$ of $\mathrm{MDH}$ and Gigli saw osteotomies, the mean $\mathrm{mHI}$ was $1.72 \pm 0.33 \mathrm{month} / \mathrm{cm}$ (range 1.2$2.5 \mathrm{month} / \mathrm{cm}$ ) and $1.54 \pm 0.36 \mathrm{month} / \mathrm{cm}$ (range 1.0-2.5 month/cm) respectively. The healing index was significantly lower in the Gigli saw group. 


\section{Cureus}

\begin{tabular}{|c|c|c|}
\hline Factor & Modified Healing Index & p-value \\
\hline Overall both groups & $1.60 \pm 0.34 \mathrm{month} / \mathrm{cm}$ & \\
\hline \multicolumn{3}{|c|}{ Technique of osteotomy } \\
\hline Multiple drill holes & $1.72 \pm 0.33 \mathrm{month} / \mathrm{cm}$ & \multirow[t]{2}{*}{0.04} \\
\hline Gigli Saw & $1.54 \pm 0.36 \mathrm{month} / \mathrm{cm}$ & \\
\hline \multicolumn{3}{|l|}{ Level of osteotomy } \\
\hline Proximal tibia & $1.59 \pm 0.34$ month $/ \mathrm{cm}$ & \multirow[t]{2}{*}{0.39} \\
\hline Distal tibia & $1.67 \pm 0.38 \mathrm{month} / \mathrm{cm}$ & \\
\hline \multicolumn{3}{|l|}{ Gender } \\
\hline Male & $1.51 \pm 0.39 \mathrm{month} / \mathrm{cm}$ & \multirow[t]{2}{*}{0.42} \\
\hline Female & $1.62 \pm 0.43 \mathrm{month} / \mathrm{cm}$ & \\
\hline
\end{tabular}

TABLE 2: Comparison of modified healing indices of different parameters

None of our patients showed nonunion at osteotomy site. However, the problems of incomplete osteotomy in two cases and bone fractures in four cases were seen in multiple drill holes osteotomy.

\section{Discussion}

In the treatment of bone lengthening and bone transport, different types of low energy osteotomies have been described in the literature [8-12]. Gigli saw and MDH osteotomy has been recommended by many orthopedic surgeons because of better bone healing with minimal trauma to the soft tissue envelope at the osteotomy site $[5-6,13]$. Although many studies have been performed to evaluate their outcome, there is limited evidence to compare the two. Some advocate that there is high osseous regeneration in Gigli saw osteotomy $[2,4,6]$, others report that there is no significant difference in bone healing between the two techniques [7].

Paktiss AS et al. performed Afghan percutaneous osteotomy in 50 tibias and $>20$ femurs and reported rapid healing, even with a relatively large amount of bone displacement. He recommended that Gigli saw osteotomy is safe, rapidly performed, and physiologically sound alternative to corticotomy [14]. In a similar study, Wardak MM et al. performed thousands of osteotomies using Gigli saw technique without facing any serious problems. According to him, the Gigli saw technique is minimally invasive, respects the periosteum, and is a low energy osteotomy that leaves a very smooth cut, and is especially important for rotational correction offering adequate regenerative properties [2].

Eralp L et al. [4] did a comparative study on two different osteotomy techniques for tibial lengthening and found that Gigli saw osteotomy patients had a less periosteal damage and significant better healing index compared with patients who underwent lengthening by MDH osteotomy (1.37 vs 1.9 months/cm), which again shows the biologic superiority of the Gigli saw osteotomy technique. However, in another comparative study of two proximal tibial osteotomy techniques by Peek AC et al., with 15 Gigli saw and 12 De Bastiani osteotomy techniques, there was no significant difference in healing indices of the two methods ( $2.2 \mathrm{vs} 1.8$ months $/ \mathrm{cm}$ ). Both Gigli saw and De Bastiani osteotomy techniques resulted in good bone formation following distraction osteogenesis [7].

In our study, the overall $\mathrm{mHI}$ of both groups was $1.60 \pm 0.34 \mathrm{month} / \mathrm{cm}$ (range 1.0-2.5 month $/ \mathrm{cm}$ ). When the two techniques were compared, the mean $\mathrm{mHI}$ was $1.72 \pm 0.33 \mathrm{month} / \mathrm{cm}$ (range $1.2-2.5 \mathrm{month} / \mathrm{cm}$ ) in MDH group and $1.54 \pm 0.36 \mathrm{month} / \mathrm{cm}$ (range 1.0-2.5 month/cm) in the Gigli saw group. The significantly low healing index of Gigli saw group $(\mathrm{p}=0.04)$ is comparable to that published in many other studies and supports Gigli saw osteotomy over MDH osteotomy technique.

Limitations of this study include its retrospective analysis and small sample size. Also, the inclusion of only tibial bone osteotomies could lead to a selection bias.

The surgeons performing these procedures recommend that if Gigli saw is passed under the bone subperiosteally by two small incisions, this will minimize the local trauma and neurovascular injury and eliminate the possibility of incomplete osteotomy and unfavorable bone cracks. This can be another favourable point to employ the Gigli saw technique. 


\section{Conclusions}

After comparing the mHI of percutaneous Gigli saw osteotomy with that of MDH osteotomy performed in patients for bone lengthening or bone transport using Ilizarov fixator, we conclude that the former respects the periosteum and soft tissue envelope around the osteotomy more than the latter, resulting in better consolidation following distraction osteogenesis. Moreover, subperiosteal application of Gigli saw proved to be safe and effective.

\section{Additional Information}

\section{Disclosures}

Human subjects: Consent was obtained by all participants in this study. Liaquat University of Medical and Health Sciences, Jamshoro issued approval 16-205. Animal subjects: All authors have confirmed that this study did not involve animal subjects or tissue. Conflicts of interest: In compliance with the ICMJE uniform disclosure form, all authors declare the following: Payment/services info: All authors have declared that no financial support was received from any organization for the submitted work. Financial relationships: All authors have declared that they have no financial relationships at present or within the previous three years with any organizations that might have an interest in the submitted work. Other relationships: All authors have declared that there are no other relationships or activities that could appear to have influenced the submitted work.

\section{References}

1. Paley D: The Ilizarov corticotomy. Tech Orthop. 1990, 5:41-52. 10.1097/00013611-199012000-00008

2. Wardak MM, Wardak E: Percutaneous Gigli saw osteotomy. Oper Orthop Traumatol. 2010, 22:414-20. 10.1007/s00064-010-9007-8

3. Catagni MA, Azzam W, Guerreschi F, Lovisetti L, Poli P, Khan MS, Di Giacomo LM: Trifocal versus bifocal bone transport in treatment of long segmental tibial bone defects. Bone Joint J. 2019, 101:162-9. 10.1302/0301-620X.101B2.BJJ-2018-0340.R2

4. Eralp L, Kocaoğlu M, Özkan K, Türker M: A comparison of two osteotomy techniques for tibial lengthening . Arch Orthop Trauma Surg. 2004, 124:298-300. 10.1007/s00402-004-0646-9

5. Yasui N, Nakase T, Kawabata H, Shibata T, Helland P, Ochi T: A technique of percutaneous multidrilling osteotomy for limb lengthening and deformity correction. J Orthop Sci. 2000, 5:104-7. 10.1007/s007760050136

6. Paley D, Tetsworth K: Percutaneous osteotomies. Osteotome and Gigli saw techniques . Orthop Clin North Am. 1991, 22:613-24.

7. Peek AC, Timms A, Chin KF, Calder P, Goodier D: Patterns of healing: a comparison of two proximal tibial osteotomy techniques. Strategies Trauma Limb Reconstr. 2016, 11:59-62. 10.1007/s11751-016-0243-9

8. De GB, Aldegheri R, Renzi-Brivio L, Trivella G: Limb lengthening by callus distraction (callotasis). J Pediatr Orthop. 1987, 7:129-34. 10.1097/01241398-198703000-00002

9. Dabis J, Templeton-Ward O, Lacey AE, Narayan B, Trompeter A: The history, evolution and basic science of osteotomy techniques. Strategies Trauma Limb Reconstr. 2017, 12:169-80. 10.1007/s11751-017-0296-4

10. Hosny GA, Ahmed AA, Hussein MA: Clinical outcomes with the corticotomy-first technique associated with the Ilizarov method for the management of the septic long bones non-union. Int Orthop. 2018, 42:2933-9. 10.1007/s00264-018-3924-9

11. Yin P, Zhang L, Li T, et al.: Infected nonunion of tibia and femur treated by bone transport . J Orthop Surg Res. 2015, 10:49. 10.1186/s13018-015-0189-5

12. Panagopoulos GN, Mavrogenis AF, Mauffrey C, et al.: Intercalary reconstructions after bone tumor resections: a review of treatments. Eur J Orthop Surg Traumatol. 2017, 27:737-46. 10.1007/s00590-0171985-x

13. Frierson M, Ibrahim K, Boles M, Bote H, Ganey T: Distraction osteogenesis. A comparison of corticotomy techniques. Clin Orthop Relat Res. 1994, 301:19-24. 10.1097/00003086-199404000-00004

14. Paktiss AS, Gross RH: Afghan percutaneous osteotomy. J Pediatr Orthop. 1993, 13:531-3. 10.1097/01241398199307000-00022 